\author{
Matilde Ribeiro \\ Secretaria Especial de Polític as de Promoção da Igualda de Racial \\ da Presidência da República do Brasil
}

\title{
0 feminismo em novas rotas e visões
}

\begin{abstract}
Resumo: O presente texto se baseia no debate proposto por Mary Hawkesworth no artigo "A semiótica de um encontro prematuro: o feminismo em uma era pós-feminista", orientando-se por um olhar latino-a meric a no-c a rib enho sobre as tra nsformações do feminismo e as conquistas das mulheres em momentos cruc iais dessa artic ula ção, relembrando fa ses memorá veis como a renovação dos idea is feministas, a a utonomia do movimento de mulheres negras e sua interrelação com o ativismo negro e feminista, articulações internacionais sintonizados com a realidade/diversidade brasileira e a incorporação da agenda feminista nas instâncias governamentais. A autora expõe o dinamismo e a capacidade de retroa limentação do feminismo brasileiro, carac terístic as que possibilitam a força necessária para sua sobrevivência e inovações harmonizadas com a evolução de valores socia is diante das conquistas decorrentes de sua existência nos cenários local, regional e global. Substancialmente, desenvolve o texto com ênfase no ativismo local como desencadeador de uma ação efetiva de Estado para eqüidade de gênero e raça.
\end{abstract}

Pa la vras-chave: feminismo; mulheres negras; rac ismo; polític as públic as; ações governa menta is.

Copyright 2006 by Revista Estudos Feministas.

${ }^{1}$ Frases do poema "A essas e tantas outras", public ado no Dicionário Mulheres do Brasil (Sc huma SC HUMAHER e Éric o Vital BRAZIL, 2000). No decorrer do texto serão utilizadas na introdução de cada capítulo. 2 HAWKESWO RTH, 2006

${ }^{3}$ Texto escrito com a colaboração de Angelita Garcia, socióloga e assistente de programa do Unifem (Fundo de Desenvolvimento das Nações Unidas para a Mulher), e Isa bel Clavelin, joma lista, à s qua is agradeço pela inspiração e paciência no diálogo.

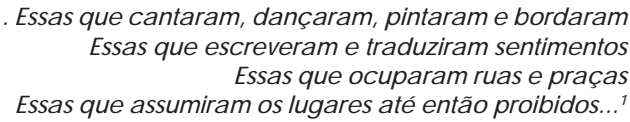

.. Essa s que cantaram, dançaram, pintaram e bordaram Essas que escreveram e traduziram sentimentos Essas que ocuparam ruas e praças

Essas que assumiram os lugares a té então proibidos... ${ }^{1}$

\section{Para começo de conversa}

Como se tivesse participando de uma rodada de diálogo, reflito em voz alta e elaboro possíveis respostas às indagações sobre os rumos do feminismo. Por puro exercício de imaginação, interagimos - Mary Ha wkesworth, autora do texto "A semiótica de um encontro prematuro: o feminismo em uma era pós-feminista", ${ }^{2}$ algumas mulheres que citarei adiante, as colaboradoras deste $\operatorname{artig}^{3} \mathrm{e}$ eu. 
${ }^{4}$ HAWKESWORTH, 2006, p. 739.

${ }^{5}$ HAWKESWORTH, 2006, p. 746.

${ }^{6}$ ALVAREZ, 1998.
Ha wkesworth nos brinda com uma instigante a nálise sobre as perspectivas do feminismo. De um lado, constata que o feminismo experimenta um visível crescimento, seja em sua sba ses orga niza tivas, seja em seus reflexos em ma res nunca antes navegados - pelo menos com a intensidade com que tem sido tra ta do pelos caminhos do "gênero" nos espaç os multila tera is (em especial nas instâncias da ONU), no interior de governos, na academia, entre outros universos. Por outro viés, surgem as interrogações de que o feminismo está em sua fase terminal, a firmação saudada com "o a dvento da era pós-feminista".

Do alto de suas preocupações, Ha wkesworth classifica o fenômeno da expansão sem precedentes do feminismo e sua morte prematura como estranho. Assim, pergunta-se: "Como podemos interpretar ta is notícias da morte do feminismo? Diante do entusiasmo e variedade das formas proliferativas da teoria e da prática feminista, qual o significado do enterro prematuro do feminismo?". ${ }^{4}$ Com essa sindagações, inicia-se um interessante pulsar de idéias. Na busca de respostas, destaca duas hipóteses para a suposta morte do feminismo: a) o "obituário", como um conjunto de idéias que revelam mudanças no campo feminista como abandono do propósito original conscientização, polític a confrontacional e afirmação de band eiras de luta. Como se o feminismo tivesse se esgota do com o tempo; e b) "extinção evoluc ioná ria", demonstrando a proposição de um processo de seleção natural, como se fosse fatalidade. Trata-se aqui da visão pós-feminista como uma forte convicção de que a visão feminista "extinguiu-se ou logo se extinguirá", ou que "o pós-feminismo é um marcador de tempo assim como de espaço, sugerindo uma seqüência temporal na qual o feminismo foi transcendido, ocluído, ultrapassado [...] se foi, partiu, morreu".5

Essa conversa nos remete a aprofundamentos e a nálises orientadas pela visão e acúmulo do ativismo brasileiro e latino-americano-caribenho. Somando-se à vivência internacional do feminismo, emergem certeza sde que não é hora de decretaro fim desse movimento. Aliás, essa morte dificilmente ocorrerá, pois esse movimento, como um fio condutor para mudanças, não deixa de existir, transforma-se e moderniza-se.

Hawkesworth traz em seu texto uma formulação de Sonia Alva re $z^{6}$ no trecho em que evidencia a multiplic a ção dos espaços de a tuação feminista. Partilho desse entendimento por perceber as vivacidades do feminismo no Brasil, sua trajetória de reformulações com implic ações positiva se inova doras pa ra a movimenta ção das ruas, das organizações não-governamentais, dos setores 
${ }^{7}$ SOARES, 2004, p. 162.

${ }^{8}$ AZEREDO, 1994, p. 203-216. a cadêmicos, dos governos, dos movimentos socia is. Ademais, o feminismo alastra-se e traz novas personagens e realidades para a cena política.

\section{Feminismo no Brasil, buscas e inovações}

\author{
.. E as que fizeram sem pedir licença, \\ Essas que desafiaram o coro do destino \\ E as que com isso abriram as alas e as asas...
}

Abrir alas e as asas é o intuito do movimento feminista! Confrontamo-nos a seguir com muitas compreensões sobre feminismo em suas incidências políticas e institucionais. Para Vera Soares, ${ }^{7}$ o feminismo "Engloba teoria, pratica ética e toma as mulheres como sujeitos históric os da transformação da sua própria condição social. Propõe que as mulheres partam para transformar a si mesmas e a o mundo".

A a rticulação feminista propõe-se como um catalisador das mudanças socia is para as mulheres $e$ também para toda a sociedade. No entanto, não é um movimento homogêneo. Contém uma série de dificulda des de estruturação e de orquestração de sua multiplicidade, como no tratamento da diversidade entre as mulheres (racial, étnica, condição socioeconômica, orientação sexual, geração ou cultural), e também abordagem plura lista nos espaços polític os conquista dos na sociedade. Em deba tese formula ções, são demonstra das controvérsia s quanto ao crescimento da participação e ao surgimento de novas atrizes - fatores totalmente benéficos -, pois recolocam em pauta ser ou não ser feminista, os efeitos $d a$ popula rização do feminismo e, a té mesmo, a incorporação das temáticas raciais e étnicas, com seu cunho histórico de questionamento da estrutura da sociedade e também do feminismo 'tradicional' branco. Segundo Sandra Azeredo, ${ }^{8}$ devido à forma como o movimento feminista tem se organizado, a imagem da feminista tem sido caracterizada como branca, de classe média e intelec tua lizada.

Na busca de ampliação da plataforma de ação feminista, as mulheres negras teceram inúmeras críticas qua nto à invisibilidade de sua a ção política. A contestação mais direta refere-se à maneira secundarizada do tratamento de sua opressão e organização, as qua is estiveram e estão submetidas pelo sistema. Isto é, seja a tra vés do discurso, seja da produção teórica, a smulheres negras a pa rec em como 'sujeito simplícitos'. Historic a mente, a sociedade tem absorvido de forma mais eficaz as reivindicações das mulheres - brancas - como parte de um 'processo natural'. A questão racial ainda é um tabu; o 
10 Gustavo VENTURINI, Marisol RECAMAN e Suely OLVEIRA, 2004

${ }^{11}$ SC HUMAHER e BRAZL, 2000, $p$. 16. combate ao racismo, pela sua sutileza e mascaramento, não 'emplacou' como tema socialmente relevante. Essa vicissitude é denunciada por Sonia Giacomini ${ }^{9}$ quando elabora sobre a subalternidade dispensada às mulheres negras desde a resistência nos marcantes períodos da escravidão. A autora a ponta para uma visão crítica da história, condenando reducionismos como o trabalho forçado travestido de liberdade econômica, o estupro institucionalizado como sensualidade e liberdade sexual da negra e/ou mulata.

Participantes do movimento negro e feminista, as mulheresnegras, conscientes da importância de seu papel na história, visam a desmascarar situações de conflito e exclusão. Com isso, não só contribuíram para a conquista de visibilidade como sujeitos políticos, perante esses movimentose a socieda de, como ta mbém construíram um curso próprio através da constituição do movimento autônomo de mulheres negras. Com isso, lutaram e lutam para garantir a subsistência, direitos socia is e políticos, e qualidade de vida para si, seus familiares e para a comunidade. Explicitamente, a agenda política das mulheres negras transcende as questões de gênero, abarcando o combate ao racismo, à discriminação e ao preconceito racial.

De maneira geral, no início do século $X X I$, as mulheres brasileiras a nuncia ra $m$ boas mudanças em suas condições de vida na pesquisa A mulher brasileira nos espaços públic o e privado, rea liza da pela Fundação Perseu Abramo em 2001. ${ }^{10}$ Diante dos cenários da diversida de, a pesquisa trouxe elementos para o debate sobre esses conceitos entre as mulheres do ponto de vista econômico, social e racial, em especial a situação da mulhernegra. A tônica da diversidade é ressaltada na apresentação do Dicionário Mulheres do Brasil, que a tenta para o cultivo da memória das mulheres como fator de justiça a ponto de não ser banalizado o esforço individual e coletivo de milha res de brasileiras que mudaram sua condiçã o: "foram índ ias contra a violência dos colonizadores, negras contra a escra vidão, brancascontra os va lores pa tria rca is vigentes, todas lutando pela transformação das regras impostas a o feminino". ${ }^{11}$ Vale ressaltar a inserção das biografias o rienta das pelos prenomes das mulheres em vez dos nomes das famílias, pois pela história as negras e indígenas não necessariamente possuem sobrenomes.

Os processos de mudança e revisão do feminismo são vistos pelas próprias feministas, pelos setores democráticos e pelos formadores de opinião como momentos de vivacidade, de surgimento de novos conceitos e práticas. Está longe de qualquer especulação 
12 CARNEIRO, 2003.

${ }_{13}$ Matilde RIBEIRO, 1995.

${ }^{14} \mathrm{ONU}, 2002$ responsável o apontamento de morte ou finalização de joma da do movimento feminista. Em uma a valia ção crítica, são passíveis de reconhecimento os altos e baixos no processo de mobilização e formulação feminista, assim como a sua capacidade de retomada e reinserção.

A partir de 1985, é notável uma oxigenação no feminismo. Daquele período aos dias atuais, foram rea liza dos 14 Enc ontros Na c iona is Feministas (ENF) e um to ta I de dez Enc ontros Feminista s La tino-Americ a nos e do Ca ribe com expressivo aumento do número de participantes na mesma proporção da presença efetiva de setores com capacidade de interferência nesse movimento, como as mulheres oriundas da militância sindical, populare negra, elevando assim a gama de debates. Incorporada ao processo dessas transforma ções, Sueli Carneiro ${ }^{12}$ enaltece 0 enegrecimento do movimento feminista, fortalec endo o protagonismo das mulheres negras. A diversificação temática nos debates e ações no campo do movimento feminista nacional passou a ter repercussão intemacional com o advento das Conferênc ias Mundia is dos a nos 1990, como a Conferência de Direitos Humanos (Viena-1993); a III Conferência de População e Desenvolvimento (Cairo1984); a IV Conferência da Mulher (Beijing-1995), entre outras.

A Conferência de Beijing possibilitou a abertura da disc ussão sobre o feminismo e as relações ra cia is e étnic as em âmbito mundial. ${ }^{13} \mathrm{~A}$ Conferência produziu a Decla ração de Beijing' 95 , documento que reitera compromissos em prol dos direitos humanos. O uso dos termos "raça" e "etnia" gerou longa e dura divergência sobre a qual o Brasil e os Estados Unidos se manifestaram a favor da menção de a mbos para fins de dados estatístic os que pudessem gerar doc umenta ção a cerca da injustiça social. Consta ta-se que a IV Conferência demonstrou a possibilidade de diálogo e de solidariedade entre as mulheres que vivem diferentes situações socia is e raciais. Transcorridos dez anos, desenvolvem-se novas estratégias de monitoramento das políticas públicas voltadas para as mulheres, visando à construção de novos patamares de vida para elas.

Posteriormente, houve a ampliação dos debates entre as mulheres negras, as feministas e as militantes antiracistas na III Conferência Mundial de Combate ao Racismo, Discriminação Racial, Xenofobia e Intolerância Correlata, em 2001.14 O protagonismo das organizações negras e das mulheres negras brasileiras, acresc entandose à a liança com o movimento feminista, foi fundamental para o debate de gênero e políticas anti-racismo não só para o Brasil, mas também para toda a América Latina. 
Recentemente, a Conferência Regional das Américas: Avanços e Desafios no Plano de Ação contra o Racismo, Discriminação Racial, Xenofobia, e Intolerâncias Correlatas, em 2006, promoveu um diálogo entre representantes de governos e da sociedade civil relacionado ao combate a toda e qualquer distinção, exclusão, restrição ou preferência baseada na raça, cor, ascendência, origem étnica ou nacional. Às vésperas da Conferência, militantes feministas/das mulheres, mulheres negrase indígenas partic iparam do Diálogo entre Mulheres das Américas contra o Racismo e Todas as Formas de Discriminação, propiciando um balanço das principa is conquistas nos últimos cinco anos e dos desafios para a efetivação da inclusão das populações negra, indígena e outros grupos socia is vulnerá veis pela discriminação, registrado em documento formulado pelas mulheres à Conferência.

Na plenária final da Regional das Américas, os participantes reconheceram ser esse um período op ortuno para a tomada de decisões e a formulação de políticas anti-discrimina tórias, tendo em vista a discussão intemacional acerca das realidades de cada nação e a capacidade de aglutinação de forças por meio de artic ulações regiona is e globa is. Govemantes e sociedade civil salienta ra $m$ a criação de mecanismos de a ferição das polític as públic as para mensura ção da eficácia dasações govema menta is mediante acord ose tra ta dos intemaciona is acerca das temáticas de gênero e raça/etnia; estabeleceram as áreas da educação, saúde, habitação, emprego e renda e comunic ação como avanços decisivos na proposta de desenvolvimento das políticas públicas, para que contemplem a partir das especificidades problemas pertinentes às mulheres, id osos, crianç as e jovens indígenas e afrodescendentes da região.

\section{Quebrando barreiras govemamenta is}

... Eas que ultrapassa ram o limite da chegada,
Essas que levaram chibatadas e marcas de ferro quente Essas que vieram embaladas por sonhos...

A partir de sua intervenção crítica, o movimento feminista ultrapassou os limites de chegada, recriando paradigmas. A inserção de ativistas com conteúdos feminista e anti-racista nas esferas de decisão possibilita uma imediata mudança de discussão e visão política, favorecendo agendas determinantes para a promoção dessas populações renegadas pelo sistema hegemônico. Propicia uma proximidade e otimizaçãa de interlocução e resolução dos pleitos por meio de revisão e/ou correção 
${ }^{15}$ Criada em 21 de março de 2003, Dia Internacional de Combate à Discriminação Racial, a SEPPIR tem a incumbência de acompanhar e coordenar políticas, de forma transversal, com as dema is pastas ministeria is de cunho afimativo e promotor de igualdade entre as raças/etnias discriminadas negra, indígena, cigana, judaica e árabepalestina. Foi instituciona liza da pela Lei $n=10.678$, de 23 de maio de 2003. Disponível em: https:// www.presidencia gov.br/ccivil 03/ Leis/2003/L10.678.htm. Ac esso em: 19 nov. 2006.

${ }^{16}$ A SPM foi criada através da Medida Provisória 103, de 10 de janeiro de 2003, convertida na Lei no 10.683 , de 2003, para desenvolverações conjuntas com todos os Ministérios e Secretarias Especia is, tendo como desafio a incorporação das especificidades das mulheres nas polític as públicase o estabelecimento das condições necessárias para a sua plena cidadania. Disponível em: https://www.planalto.gov.br/ c civil 03/MPV/Antigas 2003/ 103.htm. Acesso em: 19 nov. 2006 daspolític a sexistentese, conseqüentemente, elevação das possibilida des da efic á cia da s polític as govema menta is a o passo que é fortalecido o diálogo com a sociedade civil. o comprometimento com o projeto político de promoção da igualdade de gênero e raça não significa a penasgarantira partic ipação desses grupos nos espaços de poder e decisã 0 , mas também fomentara qualidade e multiplic ação de quadros com a cúmulo teórico, prátic o e técnico para garantir ações consolidadas, densas e com repercussão na propagação de órgãos municipais, estaduais e federais parceiros para o desenvolvimento da agenda política governamental condizente com as demandas os movimentos feminista, de mulheres e antiracista. Compreende enfrentar um sistema político engessa do pela prática universa lista que não dá conta das especificidades, enviando, geralmente, comandos resistentes e preconceituosos diante da renovação proposta pela ordem mundial contra o racismo e o sexismo comungada pelo país em tratados internacionais e, paradoxa Imente, entreposta no momento de sua execução interna.

Em consonância com a construção histórica dos movimentos sociais, as bases da política nacional e os compromissos a ssumidos intema cionalmente, o governo b ra sileiro c riou três instrumentos instituc iona is considera dos funda menta is para o enfrenta mento das disc rimina ções: a Secretaria Especial de Políticas de Promoção da Igualda de Racial (SEPPIR); ${ }^{15}$ a Secretaria Especial de Políticas para as Mulheres (SPM); ${ }^{16}$ e a Secretaria Especial de Direitos Humanos (SEDH), todas vinculadas à Presidência da República. Essas Secretarias inauguram uma página signific a tiva no tra tamento dispensa do pelo Estado brasileiro à s iniqüida des resultantes do racismo, das discriminações e das desigualdades socia is históric as.

Mais especific a mente, pela constituição da SEPPIR, são declaradas as diretrizes governamenta is para 0 combate ao racismo e à discriminação racial em áreas decisivas para a vida individual e coletiva. No arcabouço dessa agenda política, incluem-se as estratégias de superação do racismo e outros tipos de lutas socia is - o comba te a o ma chismo, ao a dultocentrismo e à homofobia. Conseqüentemente, saltam a os olhos ações conjuga das incidentes na vida dos negros, indígenas, mulheres, crianças, adolescentes, jovens e homossexua is visando a superar situa ções de vulnerabilida de, pobreza e violência, havendo interface com vários movimentos sociais, sobretudo o feminista e o anti-racista.

Como parte dessa sestra tég ias, fora m rea liza das pelo Governo Federal concertações significativas pela SEPPIR, 
a 1a Conferência Nacional de Promoção da lgualdade Racial (CONAPIR), em 2005, e pela SPM, a 1ạ Conferência Nacional de Polític as para as Mulheres (CNPM), em 2004. Ambas configuram-se como instrumentos de continuidade dos debates nacionais e internaciona is contra as discriminações e ação efetiva do Brasil de cumprimento dos acordos internacionais, estabelecendo políticas públic as que, diferentemente da legislação e dos direitos constitucionais, priorizam, por meio dos planos naciona is de Políticas para as Mulheres e da Igualdade Racial, áreas e setores com programas e projetos que promovem uma reversão na situação de exclusão de mulheres e grupos étnic os/racia is disc rimina dos.

llustram esse compromisso do Govemo Federal para a promoção da igualdade de gênero e raça iniciativas como o Programa de Fortalecimento Institucional para Igualdade de Gênero e Raça, Erradicação da Pobreza e Geração de Emprego (GRPE), o qual prevê um esforç o para implementar uma agenda nacional de trabalho decente no Brasil por meio do fomento das políticas públicas de combate à pobreza e geração de trabalho e renda. No mundo do trabalho, a SEPPIR, SPM, Ministério do Trabalho, Federação Nacional dos Trabalhadores Domésticos e Organização Intemacional do Trabalho são parcerias no Pla no Tra balho Doméstico Cidadão, o qual visa à elevação da escolaridade, a mpliação da proteção social, fortalecimento da representação das trabalhadoras doméstic as, melhoria dascondições de trabalho e moradia, e garantia de direitos trabalhistas. Por meio do projeto Gênero, Diversidade e Orientação Sexual na Escola, professores do ensino fundamental da rede pública estão sendo formados para combater o preconceito em sala de aula. A inic ia tiva é desenvolvida pela SEPPIR, SPM, Ministério da Educação e Conselho Britânico no Brasil.

Ca be ressa lta rque muitas dessa s conc retiza ções são fruto das pressões dos movimentos socia is nos seus eixos de atuação, das categ orias profissiona is conhec edoras das demandas políticas para um trabalho digno, do compromisso do Govemo Federal em investir em áreas fundamentais para o desenvolvimento humano e da comunhão dosórgãos intemaciona is em intervir na solução dos problemas brasileiros. Enfim, o que se deseja como resultado é a igualdade de direitos para o exercício da cidadania e o respeito à diversidade em todas as suas expressões. 


\title{
4 Perspectivas com base em sonhos e realidades
}

\author{
Essas que fic aram de fora \\ E aquelas que ainda virão \\ E as que viveram por nós.
}

A história da humanidade se faz a partir das ações de pessoas e grupos que questionam o poder instituído e luta $\mathrm{m}$ pelos seus idea is. É longa a caminhada a té o patamar a Imeja do de enraizamento do projeto político contra todas as formas de discriminação, mas certamente as experiências dos últimos anos nos remetem a horizontes otimistas. As mulheres negras estiveram certas em seu processo de luta: para serem condizentes com a história, decidiram que poderiam incidir em todas as questões socia is e políticas, mas principalmente, como disse Cameiro, ${ }^{17}$ demarcaram o "toque de cor" nas propostas de gênero e no feminismo.

Para o conjunto das mulheres, cada vez mais tem sido possível deixar de lado a perspectiva revanchista e de guetiza ção da luta feminista. A ordem é ocupar todos os espaços na sociedade - o poder público, o parlamento, os meios acadêmicos, as associações, os partidos, os movimentos sociais. Essa ocupação vem acompanhada de inúmeras dificuldades, e nem sempre recheada de poder.

Como ação imediata, é preciso identificar as diferentes vertentes dos feminismos, explicitando as diferenças, encontrando os nossos comuns. É necessário reforçar o movimento feminista enquanto movimento produtor de idéias e práticas inovadoras, que questionam a estrutura social vigente - os domínios entre as nações; os mandos e desmandos do ca pital; a crista liza ção do poder como sendo atribuição masculina e branca, entre outros fatores. Toma-se ta mbém imperativo um eterno e sensível olhar para o cotidiano e ao redor da casa, mas ta mbém para a conjuntura nacional e internacional. Hoje as cercas entre os territórios estão cada vez mais tênues. É imprescindível um olhar 'planetário', porém sem perder a dimensão do chão. A infiltração dos idea is feminista s em todos os espaçosparece ser uma forma de quebrarinércias sociais.

A entrada de a tivistas feminista s/mulheres nas estruturas de govemos implica a interioriza ção dos valores feminista s/das mulheres pa ra confronto dos distúrb ios so cia is que alijam a qualidade de vida das mulheres. Significa a intervenção direta e organizada em busca de políticas públicas sintonizadas com os interesses da agenda e a 
estrutura ção de pila res que promova m uma transformação real da ordem sociopolític a brasileira.

Das conversas imaginá rias inicia is deste artigo ao seu desfecho, minhas interlocutoras e eu reiteramos que não há morte e sim modemização e definição de novos rumos e focos para o feminismo. Temos pela frente uma a tua liza ção de pensa mento sobre o alc ance do feminismo, suas conseqüências para a sociedade, suas inserções institucionais, e tantas outras questões do cotidiano das ações coletivas das mulheres que, conscientemente ou não, são feministas.

Isso nos exige cada vez mais a capacidade de conviver com ações políticas na sociedade e com a institucionalização desse feminismo, porém sem esquecer princípiose autonomia. Faz-se urgente a ocupação de mais espaços de poder que possam ser assumidos ind ividua Imente pelas mulheres e ta mbém por seus g rupos e organizações. Mas é igualmente importante e emergencial a visibilidade do movimento feminista como um movimento de contestação, que sai às ruas demarcando suas posições de rebeldia, ousadia e firmeza na construção da tão almejada justiça social.

\section{Referências bibliográficas}

ALVAREZ, Sonia. "Feminismos la tinoa meric anos: reflexiones teóricas y perspectivas comparativas". In: RíOS TOBAR, Marcela (Org.). Reflexiones teóricas y comparativas sobre los feminismos en Chile y America Latina. Santiago: Notas del Conversa torio, 1998. p. 4-22.

AZEREDO, Sandra. "Teorizando sobre gênero e relações raciais". Revista Estudos Feministas, número especial, p. 203-216, 2. sem. 1994.

CARNEIRO, Sueli. "Enegrecer o feminismo: a situação da mulher negra na América Latina a partir de uma perspec tiva de gênero". In: ASHOKA EMPREENDIMENTOS SOCIAIS; TAKANO CIDADANIA (Orgs.). Racismos contemporâneos. Rio de J a neiro: Ta ka no Editora, 2003. p. 49-58.

CONFERÊNCIA NAC IONAL DE POĹTCCAS PARA AS MULHERES, 1., 2004, Brasília. Anais... Bra sília: SPM, 2004. Disponível em: http://www.presidencia.gov.br/estrutura_presidencia/ sepm/.arquivos/integra_a nais Acesso em: 3 nov. 2006.

CONFERÊNCIA NACIONAL DE PROMOÇÃO DA IGUALDADE RACIAL, 1., 2006, Brasília. Rela tório Final. Bra sília: Seppir, 2006. Disponível em: http://www.pla na lto.gov.br/seppir/ publicacoes/relatorio_final_conapir.pdf Acesso em: 3 nov. 2006. 
CONFERÊNCIA REGIONAL DAS AMÉRICAS, 1., 2006, Brasília. Resumo da Plenária Final. Brasília: Seppir, 2006. Disponível em: http://www.planalto.gov.br/seppir/ publicacoes/reuniao_plenaria_final.pdf Acesso em: 3 nov. 2006.

GIACOMINI, Sonia Maria. Mulher e escrava. Petrópolis: Vozes, 1988.

HAWKESWORTH, Mary. "A semiótica de um encontro prematuro: o feminismo em uma era pós-feminista". Revista Estudos Feministas, v. 14, n. 3, p. 737-763, 2006.

ONU - ORGANIZAÇÃO DAS NAÇÕES UNIDAS. Declaração e Plano de Ação de Durban da III Conferência Mundial de Combate ao Racismo, Discriminação Racial, Xenofobia e Intolerância Correlata. Brasília: Fundação Cultural Pa Imares, 2002.

RIBEIRO, Matilde. "Mulheres negras brasileiras: de Bertioga a Beijing". Revista Estudos Feministas, v. 3, n. 2, p. 446457, 1995.

SC HUMAHER, Schuma; BRAZL, Érico Vital (Orgs.). Dic ionário Mulheres do Brasil: de 1500 até a atualidade. Rio de Ja neiro: J orge Zahar Ed., 2000.

SOARES, Vera. "O feminismo e o machismo na percepção das mulheres brasileira s". In: VENTURINI, Gustavo; RECAMAN, Marisol; OLIVEIRA, Suely (Orgs.). A mulher brasileira nos espaços público e privado. 1. ed. São Paulo: Editora e Fundação Perseu Abra mo, 2004. p. 161182.

VENTURINI, Gusta vo; RECAMAN, Ma risol; O LIVEIRA, Suely (Orgs.). A mulher brasileira nos espaços público e privado. 1. ed. São Paulo: Editora e Fundação Perseu Abramo, 2004.

[Recebido em dezembro de 2006 e a ceito para publicação em dezembro de 2006]

\section{Feminism on New Routes and Views}

Abstract: This paper is based on the debate proposed by Mary Hawkesworth in "The semiotic s of a Premature Burial: Feminism in a Post-Feminist Age". It is guided by a Latin-American and Caribbean view of the transformations of feminism and of women's achievements in critical moments of that artic ulation, rec ollecting outstanding periods such as the renovation of feminist id eals; the autonomy of the black women's movement and its inter-relation with black and feminist activism; and international articulations tuned with Brazilian reality/diversity and with the incorporation of the feminist agenda within governmental instances. The author portrays how the verve and retro-feeding capacity of Brazilian feminism provide the necessary strength for its survival, as well as for its innovations which a re consonant with the evolution of social values, leading to its various achievements as they stem from local, regional and global arenas. Substantially, the author has developed this text with a sharp focus on loc al activism as the trigger for effec tive governmental action towards a chieving gender and race equity.

Key Words: Feminism; Black Women; Rac ism; Public Policy; Governmental Action. 